\title{
Lipoprotein(a)—an interdisciplinary challenge
}

\author{
U. Julius ${ }^{1}$ S. Tselmin ${ }^{1}$ U. Schatz ${ }^{1}$ S. Fischer ${ }^{1}$ S. R. Bornstein ${ }^{1}$ \\ Published online: 5 March 2019 \\ (c) The Author(s) 2019
}

\begin{abstract}
Lipoprotein(a) (Lp(a)) is an internationally recognized atherogenic risk factor which is inherited and not changed by nutrition or physical activity. At present, only proprotein convertase subtilisin/kexin type 9 (PCSK9) inhibitors may modestly decrease its concentration (but not in all patients)—-leading to a certain decrease in cardiovascular events (CVE) in controlled studies. However, at present an elevation of $L p(a)$ is not a generally accepted indication for their use. More effective is lipoprotein apheresis (LA) therapy with respect to both lowering Lp(a) levels and reduction of CVE. In the future, an antisense oligonucleotide against apolipoprotein(a) will probably be available. Atherosclerosis in patients with an elevation of Lp(a) may affect several vessel regions (carotids, aorta, coronaries, leg arteries). Thus, Lp(a) should be measured in high-risk patients. These patients are usually cared for by their family doctors and by other specialists who should closely cooperate. Lipidologists should decide whether costly therapies like PCSK9 inhibitors or LA should be started. The main aim of current therapy is to optimize all other risk factors (LDL cholesterol, hypertension, diabetes mellitus, body weight, renal insufficiency). Patients should be regularly monitored (lab data, heart, arteries). This paper describes the duties of physicians of different specialties when caring for patients with high Lp(a) concentrations.
\end{abstract}

Keywords LDL cholesterol · Cardiovascular events · PCSK9 inhibitors · Physicians · Lipoprotein apheresis

\section{Lipoprotein(a)—an internationally accepted risk factor for cardiovascular events}

Lipoprotein(a) (Lp(a)) was detected in 1963 [1]. It contains an LDL particle to which apolipoprotein(a) is bound. In the 1990s studies showed an independent association between elevated $\mathrm{Lp}$ (a) levels and the incidence of cardiovascular events [2-4]. Recently, more epidemiological studies have documented the atherogenic risk of increased Lp(a) concentrations [5-11]. This risk has been confirmed by studies using a Mendelian randomization and genome-wide associations $[6,12]$. Mechanisms leading to atherosclerosis include direct atherogenic, proinflammatory and procoagulant activities. However, they are not yet completely understood [13]. It is of note that aortic valve stenosis is another possible consequence of high $\mathrm{Lp}$ (a) concentrations [14].

This article is part of the special issue "Lp(a) - Update 2018"

U. Julius

ulrich.julius@uniklinikum-dresden.de

1 Lipidology and Center for Extracorporeal Treatment, Department of Internal Medicine III, University Hospital Carl Gustav Carus, Technische Universität Dresden, Fetscherstr. 74, 01307 Dresden, Germany

\section{Lipoprotein(a)_role in the general population}

The incidence of elevated $\mathrm{Lp}$ (a) concentrations in a given population depends on the criterion which is used. Assuming a rather high cut-off level, elevated $L p(a)$ levels were observed in 10 to $20 \%$ of a given population [5, 12, 15]. $\mathrm{Lp}(\mathrm{a})$ is not influenced by nutritional factors or by physical activity. A hormone deficit in postmenopausal women or renal diseases may increase its concentration. Patients with a familial hypercholesterolemia often show elevated Lp(a) levels [16].

There is no doubt that not all subjects with high $\operatorname{Lp}(a)$ levels show atherosclerotic lesions. The reasons are still quite unclear. The composition of $\mathrm{Lp}(\mathrm{a})$ particles may be different. Additional factors most probably play a role: a positive family history with respect to early cardiovascular events in first-degree relatives, cigarette smoking, hypertension, elevation of low density lipoprotein cholesterol (LDL-C), diabetes mellitus, or a procoagulative situation. Thus, a healthy lifestyle and in many patients drug therapy are required to avoid or to minimize these additional factors in persons with an elevated $\mathrm{Lp}(\mathrm{a})$ risk.

Routine measurement of $\mathrm{Lp}(\mathrm{a})$ levels in a general population is challenging due to financial reasons. Measurements should focus on individuals with high atherogenic risk as listed in Table 1; [17, 18]. 
Table 1 Persons in whom Lp(a) should be measured [17, 18]

Premature acute coronary syndromes (as well as other atherosclerotic cardiovascular disease (CVD) without apparent cause, e. g. cryptogenic stroke)

Familial hypercholesterolemia

Family history of premature CVD or elevated Lp(a)

At least 5-7.5\% 10-year risk of CVD (or at intermediate risk based on other available risk scores)

Individuals with recurrent atherosclerotic cardiovascular events on appropriate secondary prevention therapy

$\operatorname{Lp}($ a) lipoprotein(a)

In 2017, Afshar and Thanassoulis [18] also suggested to measure Lp(a) levels in patients with LDL-C levels above $3.5 \mathrm{mmol} / \mathrm{l}(135 \mathrm{mg} / \mathrm{dl})$, who would otherwise not qualify for statin therapy based on available guidelines.

At least in Germany, Lp(a) is recognized as an atherogenic risk factor. In 2008 the Joint Federal Committee (Gemeinsamer Bundesausschuss) accepted an isolated elevation of $\mathrm{Lp}(\mathrm{a})$ as an indication for lipoprotein apheresis (LA) therapy [19] which is a prerequisite for being reimbursed by health insurance companies.

Fig. 1 depicts the authorities, institutions, societies, organizations, and persons involved in the management of patients who were identified to have an increased cardiovascular risk due to elevated $\mathrm{Lp}(\mathrm{a})$ concentrations.

As $\mathrm{Lp}(\mathrm{a})$ is not yet well-known in the population and especially among treating physicians, this paper aims to give an overview about the current situation concerning the diagnostic and therapeutic options.
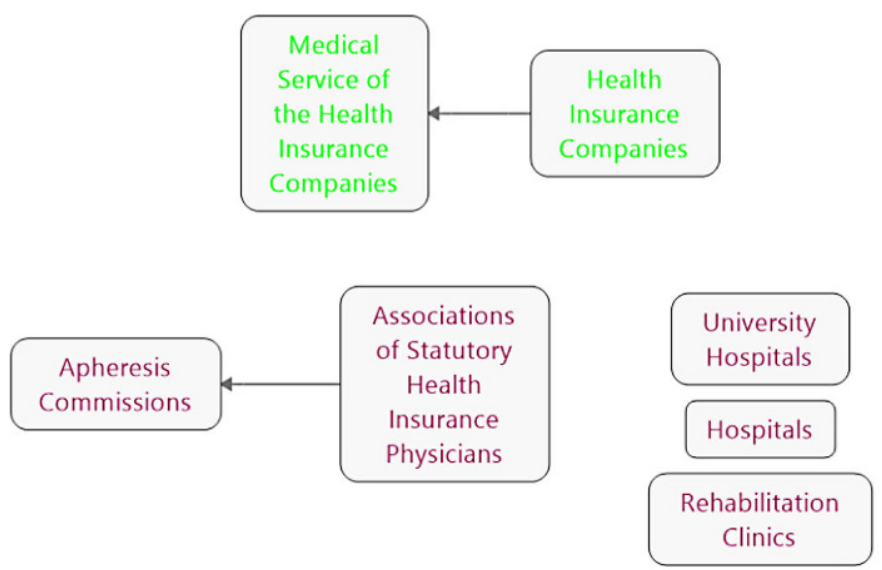

\section{Lipoprotein(a)-role in the health care system}

\section{Medical specialties playing a central role}

Fig. 2 summarizes the medical specialties involved in the care for patients with elevated $\mathrm{Lp}$ (a) levels. The vast majority of these patients are seen as outpatients, but severe complications like myocardial infarction, stroke or vascular interventions require hospitalization.

Physicians marked in red in Fig. 2 play a prominent role when attending patients with high Lp(a) levels - their tasks are described in more detail in the following.

\section{Family doctors/general practitioners}

The family doctor usually knows the family history of his patients very well and thus can identify high-risk patients whose first-degree relatives suffered from a cardiovascular event at an early age (less than 60 years) or who have high Lp(a) levels. He should also consider checking Lp(a) levels of other family members who have not yet suffered a cardiovascular event (Fig. 3).

Many family doctors regularly determine lipid concentrations of their patients, but some of them do not measure $\mathrm{Lp}(\mathrm{a})$ - mainly due to underestimation of the problem "Lp(a)" or for financial restrictions. In high-risk patients, lipids should be checked at least twice per year.

They should advise patients at risk to maintain a healthy lifestyle (especially no smoking). Usually they pay attention to possible concomitant diseases like hyperlipoproteinemia (elevation of LDL-C or/and triglycerides (TG)), hypertension, diabetes mellitus, slight renal insufficiency. Furthermore, regular vascular and cardiological examinations are
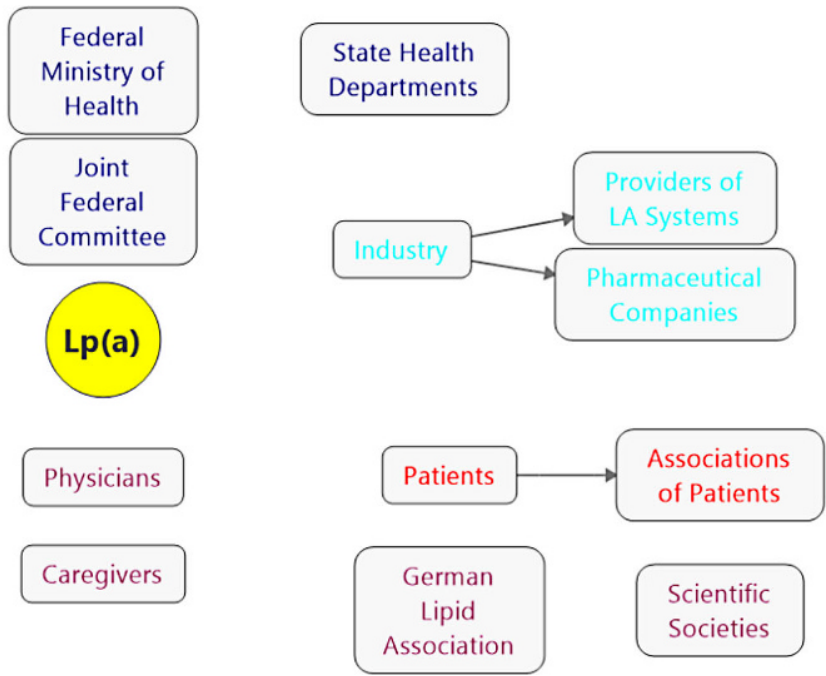

Fig. 1 Institutions and persons involved in the care for patients with elevated $L p(a)$. $L A$ lipoprotein apheresis, $L p(a)$ lipoprotein(a) 
Fig. 2 Physicians involved in the care for patients with elevated $L p(a) . L p(a)$ lipoprotein(a)

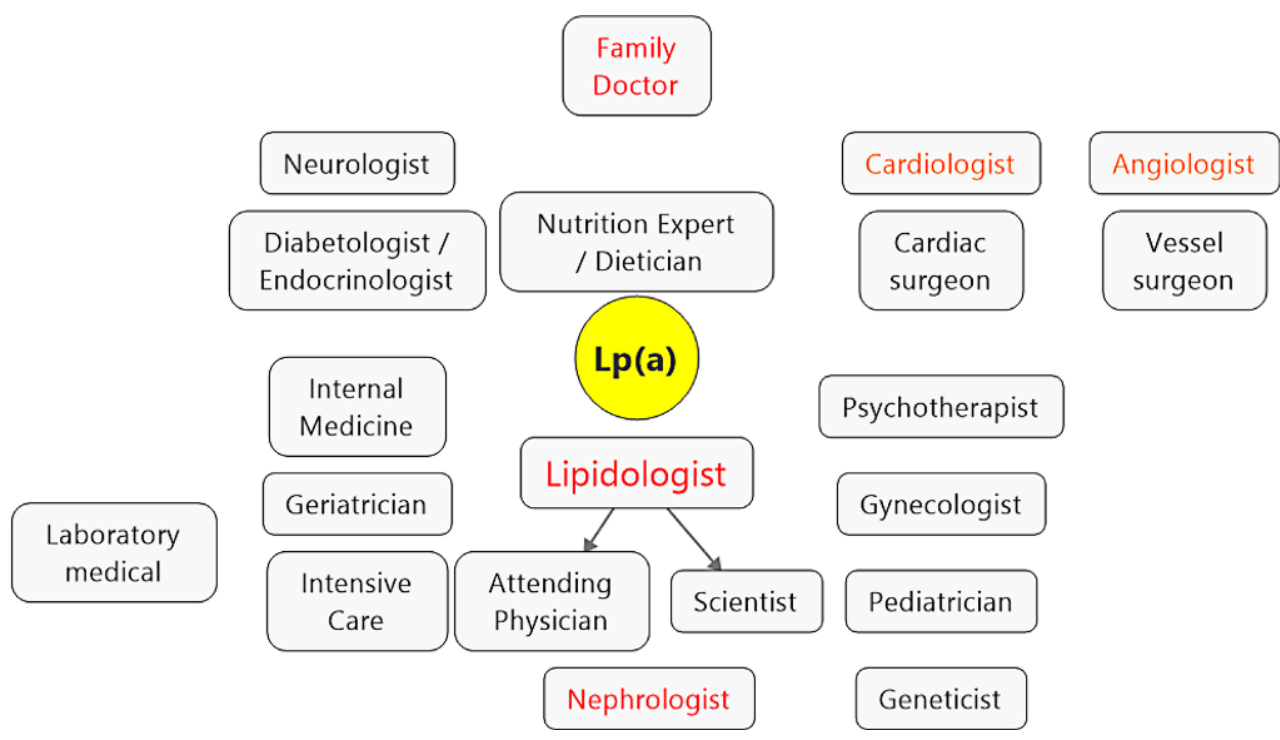

Fig. 3 Role of family doctors. $L p(a)$ lipoprotein(a)

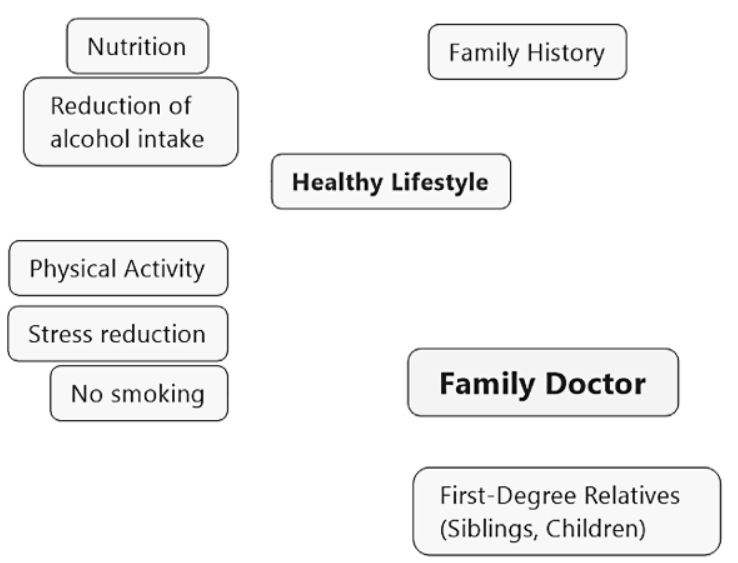

Measuring Lp(a)
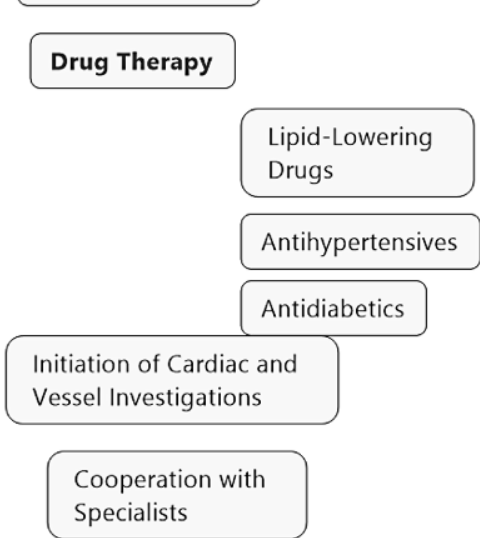

important as well as a close cooperation with other specialists who may be contacted in case of complex situations, especially when progression of atherosclerosis has been documented.

\section{Lipidologists}

The major aim of referring patients to lipidologists is to improve the current risk situation with respect to lipoprotein concentrations (Fig. 4). The goal is to reach internationally recommended target levels for LDL-C-below $1.8 \mathrm{mmol} / \mathrm{l}$ $(70 \mathrm{mg} / \mathrm{dl})$ in high-risk patients [17]. Statin therapy is often modified (increase in dose or switch to another statin when an intolerance is reported); sometimes ezetimibe is added. However, these drugs do not exert a decreasing effect on Lp(a) levels. Proprotein convertase subtilisin/kexin type 9 (PCSK9) inhibitors effectively reduce LDL-C levels and can be started in therapy-resistant patients (Fig. 4).
After the withdrawal of nicotinic acid from the European market, the following therapeutic options to reduce $\mathrm{Lp}(\mathrm{a})$ levels are available:

1. PCSK9 inhibitors - decrease Lp(a) by a mean of about $20 \%$ (ranging between 0 and 44\%); in some patients a reduction cannot be achieved. In two prospective controlled large studies, both evolocumab and alirocomab induced a modest reduction of cardiovascular events which was the consequence of decreasing $\mathrm{Lp}$ (a) levels-independently of the effects on LDL-C [20]. Up to now, an elevation of $L p(a)$ is no accepted indication for this injection therapy.

2. LA-when comparing the $L p(a)$ levels before initiation of the extracorporeal therapy with those measured during weekly LA sessions (interval mean values) - a decrease of about $50 \%$ is realistic. In two studies, cardiovascular events were reduced by about $80 \%$ [21-23]. This corresponds with the experience of other authors [24-27]. 
Fig. 4 Role of lipidologists. PCSK 9 proprotein convertase subtilisin/kexin type 9

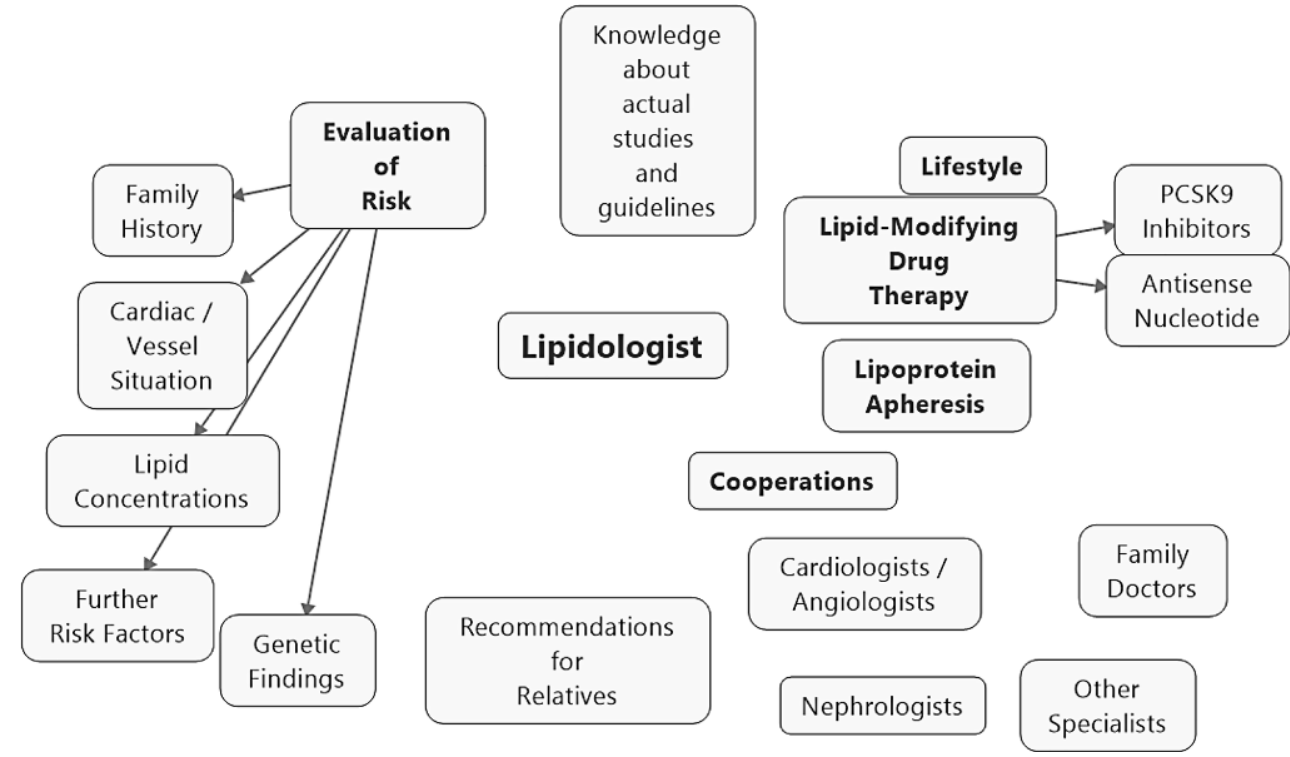

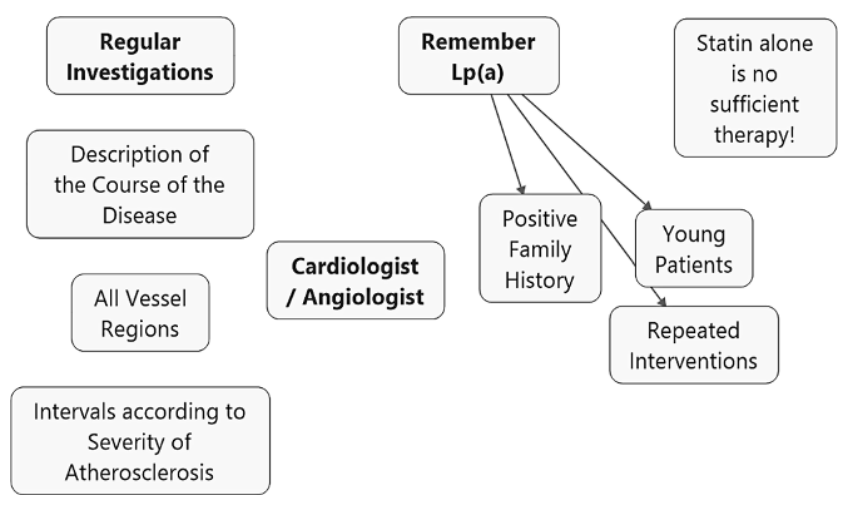

Fig. 5 Role of cardiologists/angiologists. $L p(a)$ lipoprotein(a)

The Joint Federal Committee defined three conditions before an LA therapy can be started:

a. $\mathrm{Lp}$ (a) value $\geq 60 \mathrm{mg} / \mathrm{dl}(120 \mathrm{nmol} / \mathrm{l})$,

b. LDL-C in the optimal range (usually below $1.8 \mathrm{mmol} / \mathrm{l}$ $[70 \mathrm{mg} / \mathrm{dl}])$,

c. A progression of atherosclerosis, either clinically or documented by imaging techniques [19].

Lipidologists are required to assess the total atherogenic risk of a given patient before recommending LA treatment. Some lipidologists are allowed to perform LA themselves. Some health insurance companies require that their medical services supervise the indication for LA therapy in a few cases.

The ongoing lipid-modifying drug and LA therapy are regarded as satisfactory when no progression of atherosclerotic lesions (no new events) occurs. Usually patients are seen in outpatient departments once every 3 months, in LA centers weekly.
In the future, an antisense oligonucleotide against apolipoprotein(a) will probably be available [28, 29]. A phase III study will be started in 2020. However, outcome data are needed before this therapeutic approach will play a major role in daily practice.

\section{Cardiologists/Angiologists}

Some specialists do not measure $\mathrm{Lp}$ (a) concentrations; their lab budget is rather restricted. However, an increasing number of them pay attention to this parameter in patients who are at high cardiovascular risk (Table 1) and recommend the family doctor to measure $\operatorname{Lp}(a)$ or to send the patient to a lipidological center. According to German regulations, cardiologists/angiologists are authorized to prescribe PCSK9 inhibitors. However, this is currently only done in rare cases.

The usual investigations like cardiac ultrasound and ergometry do not provide an exact follow-up of coronary atherosclerosis, while cardiac catheterization is only indicated under defined conditions and may lead to adverse events. Non-invasive techniques like computed tomography (CT) or magnetic resonance imaging (MRI) will most probably play an increasing role in the future. Aortic valve stenosis, which can be seen in patients with a high $\mathrm{Lp}$ (a) level, can be easily assessed by echocardiography.

As any vascular region may be affected by atherosclerosis it is important to examine limb and carotid arteries and the aorta as well (Fig. 5).

Two important points should still be mentioned:

1. The current findings should always be compared with previous data-to document or exclude progression of atherosclerosis. 
Fig. 6 Role of nephrologists. $L p(a)$ lipoprotein(a), PCSK 9 proprotein convertase subtilisin/kexin type 9

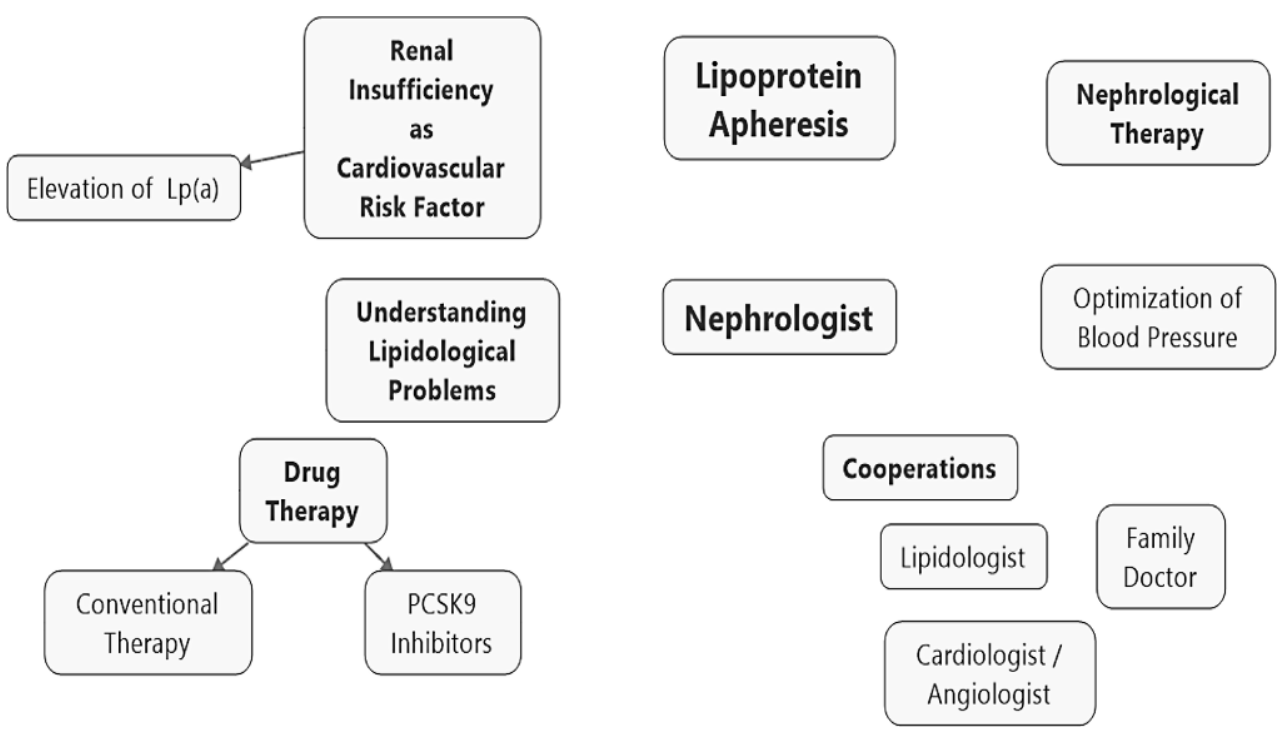

2. Patients should be offered a date for the next examination-the interval (usually annually or biannually) depends on the severity of the arterial lesions. Most patients have to be persuaded to be followed-up.

Of course, cardiac surgeons and vessel surgeons should send their patients for $L p(a)$ evaluation following invasive procedures.

\section{Nephrologists}

Renal diseases may increase $\mathrm{Lp}$ (a) concentrations. Other lipids are also influenced.

Nephrologists should regularly measure lipid concentrations and should treat disorders, if possible, in cooperation with lipidological and vascular specialists (Fig. 6).

Nephrologists have the right to prescribe PCSK9 inhibitors and can apply for permission to perform LA therapy. Of course, in apheresis patients attention should also be paid to other risk factors. For application to start or to continue LA therapy lipidological and cardiological/ angiological evaluations are required, which confirms the relevance of the mentioned close cooperation with other specialties (Fig. 2).

\section{Nutritionists}

Healthy nutrition is the basis for treating patients with lipid disorders. Though $\mathrm{Lp}(\mathrm{a})$ is not changed by nutritional factors, LDL-C and TG can be improved. Thus all high-risk patients with high $\mathrm{Lp}(\mathrm{a})$ levels should be advised.

\section{Diabetologists, endocrinologists, specialists in internal medicine}

These specialists see patients with hyperlipidemia, metabolic vascular syndrome, hypertension, diabetes mellitus, obesity, and endocrine disorders. In these patients $L p(a)$ should be measured. According to the official rules, physicians who are specialists in both diabetology and endocrinology are allowed to prescribe PCSK9 inhibitors. In complex situations, consultation with a lipidologist is recommended.

\section{Laboratory medicals}

It is an accepted opinion that measuring $L p(a)$ once in a lifetime is sufficient. However, as daily routine has shown that Lp(a) levels vary; patients with high levels or those who undergo $\mathrm{Lp}(\mathrm{a})$-lowering therapy require repeated measurements [30].

\section{Neurologists}

An ischemic stroke may be a consequence of an elevation of $\mathrm{Lp}(\mathrm{a})$, even in children [31, 32]. Neurologists should remember this cause, should measure $\mathrm{Lp}(\mathrm{a})$ and as a consequence should forward these patients to vascular or lipidological specialists.

\section{Geriatricians}

In very old patients $\mathrm{Lp}$ (a) does not have a prognostic significance-high-risk patients already die at a younger age, although with an increasing quality of medical care, the life expectancy of patients with high Lp(a) levels will probably increase. These patients will need continued medical care 
even beyond the age of 80 years in order to prevent new cardiovascular events.

\section{Gynecologists}

Pregnancies affect lipid concentrations. Data on $L p(a)$ are contradictory; sometimes an elevation was seen [33]. Some authors suspected a relationship with pre-eclampsia [34]. It appears to be possible that $\mathrm{Lp}$ (a) induces abortions [35, 36]. Hormone replacement therapy post-menopause will decrease Lp(a) concentrations [37].

\section{Pediatricians}

An elevation of $L p(a)$ is an inherited disease. In children of parents who suffered from cardiovascular complications associated with high $\mathrm{Lp}$ (a) levels this parameter should be measured, in older children an ultrasound examination of the carotids is indicated. When $\mathrm{Lp}$ (a) levels are elevated, follow-up assessments should be performed. Smoking should be avoided. In children with familial hypercholesterolemia appropriate therapeutic options should be started (statins, apheresis, etc.) according to the existing guidelines.

\section{Psychotherapists}

Patients who suffered from cardiovascular events may need the help of a psychotherapist. The risk of new events is rather high. On the other hand, relatives of affected patients may worry about their own future.

\section{Geneticists}

The Lp(a) levels are determined by the number of kringles-IV type 2 (low numbers are associated with high $L p(a)$ levels) and by certain mutations in the $\mathrm{Lp}(\mathrm{a})$ gene. The atherogenic risk of $L p(a)$ is depicted by its level-currently measuring the kringles' number or looking for gene mutations does not play a role in medical practice. However, new findings in the future may change this attitude.

\section{Specialists in intensive medicine}

Patients with previous myocardial infarction or stroke may have been in critical conditions needing intensive care. After recovery $L p(a)$ measurements in these patients are mandatory, especially in young age [38].

\section{Activities of the German Lipid Association (Lipid-Liga)}

The German Lipid Association (Lipid-Liga) offers courses to acquire the qualification of a lipidologist. $L p(a)$ is an important topic in these courses. The number of these specialists is steadily increasing. However, there are regions where no lipidologist is available yet.

Moreover, the German Lipid Association (Lipid-Liga) proposes a certification of lipidological outpatient clinics or lipidological competence centers and networks [39]. Close cooperation with specialists working in the fields mentioned in this paper is an important feature of these structures. This Association also organizes symposia dealing with lipidological issues, sometimes in cooperation with other societies (internal medicine, cardiology, angiology, nephrology).

\section{Conclusions}

An elevation of $L p(a)$ concentrations is associated with a high cardiovascular morbidity and mortality. High-risk patients need special attention. The German government is willing to spend money for these purposes and physicians should use the available diagnostic and therapeutic opportunities.

All physicians caring for patients with lipid disorders should attend meetings where lipidological topics are presented. Thus a high degree of qualification will be guaranteed. Close cooperation of different medical specialties is needed. $L p(a)$ really represents an interdisciplinary challenge.

Conflict of interest U. Julius: honoraria from Aegerion, Akcea, Amgen, Amryt, Chiesi, Sanofi, Kaneka, Diamed, Fresenius Medical Care, MSD. S. Tselmin: received honoraria for lectures and consulting by Amgen, Fresenius Medical Care, Kaneka, MSD, and Sanofi-Aventis. U. Schatz: No conflicts of interest relevant to this publication. S. Fischer: honoraria from Sanofi, Amgen, MSD, Berlin-Chemie, Abbott, Boehringer Ingelheim. S.R. Bornstein declare that he has no competing interests.

Open Access This article is distributed under the terms of the Creative Commons Attribution 4.0 International License (http:// creativecommons.org/licenses/by/4.0/), which permits unrestricted use, distribution, and reproduction in any medium, provided you give appropriate credit to the original author(s) and the source, provide a link to the Creative Commons license, and indicate if changes were made.

\section{References}

1. Berg K (1963) A new serum type system in man-the LP system. Acta Pathol Microbiol Scand 59:369-382

2. Assmann G, Schulte H, von Eckardstein A (1996) Hypertriglyceridemia and elevated lipoprotein(a) are risk factors for major coronary events in middle-aged men. Am J Cardiol 77(14):1179-1184 
3. Kostner KM, Kostner GM (2017) Lipoprotein (a): a historical appraisal. J Lipid Res 58(1):1-14. https://doi.org/10.1194/jlr. R071571

4. Cremer P, Nagel D, Mann H, Labrot B, Muller-Berninger R, Elster $\mathrm{H}$ et al (1997) Ten-year follow-up results from the Goettingen Risk, Incidence and Prevalence Study (GRIPS). I. Risk factors for myocardial infarction in a cohort of 5790 men. Atherosclerosis 129(2):221-230

5. Nordestgaard BG, Chapman MJ, Ray K, Boren J, Andreotti F, Watts GF et al (2010) Lipoprotein(a) as a cardiovascular risk factor: current status. Eur Heart J 31(23):2844-2853. https://doi.org/10.1093/ eurheartj/ehq386

6. Tsimikas S (2017) A test in context: lipoprotein(a): diagnosis, prognosis, controversies, and emerging therapies. J Am Coll Cardiol 69(6):692-711. https://doi.org/10.1016/j.jacc.2016.11.042

7. Tselmin S, Muller G, Gelgaft E, Fischer S, Julius U (2015) An elevated lipoprotein(a) plasma level as a cardiovascular risk factor. Atheroscler Suppl 18:257-262. https://doi.org/10.1016/j. atherosclerosissup.2015.02.038

8. Waldeyer C, Makarova N, Zeller T, Schnabel RB, Brunner FJ, Jorgensen $\mathrm{T}$ et al (2017) Lipoprotein(a) and the risk of cardiovascular disease in the European population: results from the BiomarCaRE consortium. Eur Heart J 38(32):2490-2498. https://doi.org/ 10.1093/eurheartj/ehx166

9. Zewinger S, Kleber ME, Tragante V, McCubrey RO, Schmidt AF, Direk K et al (2017) Relations between lipoprotein(a) concentrations, LPA genetic variants, and the risk of mortality in patients with established coronary heart disease: a molecular and genetic association study. Lancet Diabetes Endocrinol 5(7):534-543. https://doi. org/10.1016/S2213-8587(17)30096-7

10. Willeit P, Ridker PM, Nestel PJ, Simes J, Tonkin AM, Pedersen TR et al (2018) Baseline and on-statin treatment lipoprotein(a) levels for prediction of cardiovascular events: individual patient-data meta-analysis of statin outcome trials. Lancet 392(10155):1311-1320. https://doi.org/10.1016/S0140-6736(18) 31652-0

11. Langsted A, Kamstrup PR, Nordestgaard BG (2019) High lipoprotein(a) and high risk of mortality. Eur Heart J. https://doi.org/10. 1093/eurheartj/ehy902

12. Kronenberg F (2016) Human genetics and the causal role of lipoprotein(a) for various diseases. Cardiovasc Drugs Ther 30(1): 87-100. https://doi.org/10.1007/s10557-016-6648-3

13. Tsimikas S, Fazio S, Ferdinand KC, Ginsberg HN, Koschinsky ML, Marcovina SM et al (2018) NHLBI working group recommendations to reduce lipoprotein(a)-mediated risk of cardiovascular disease and aortic stenosis. J Am Coll Cardiol 71(2):177-192. https:// doi.org/10.1016/j.jacc.2017.11.014

14. Kamstrup PR, Tybjaerg-Hansen A, Nordestgaard BG (2013) Elevated lipoprotein(a) and risk of aortic valve stenosis in the general population. J Am Coll Cardiol 63(5):470-477. https://doi.org/10. 1016/j.jacc.2013.09.038

15. Kamstrup PR, Tybjaerg-Hansen A, Nordestgaard BG (2011) Lipoprotein(a) and risk of myocardial infarction-genetic epidemiologic evidence of causality. Scand J Clin Lab Invest 71(2):87-93. https://doi.org/10.3109/00365513.2010.550311

16. Li S, Wu NQ, Zhu CG, Zhang Y, Guo YL, Gao Y et al (2017) Significance of lipoprotein(a) levels in familial hypercholesterolemia and coronary artery disease. Atherosclerosis 260:67-74. https://doi. org $/ 10.1016 / j$.atherosclerosis.2017.03.021

17. Catapano AL, Graham I, De Backer G, Wiklund O, Chapman MJ, Drexel H et al (2016) 2016 ESC/EAS Guidelines for the Management of Dyslipidaemias. Eur Heart J 37(39):2999-3058. https://doi. org/10.1093/eurheartj/ehw272

18. Afshar M, Thanassoulis G (2017) Lipoprotein(a): new insights from modern genomics. Curr Opin Lipidol 28(2):170-176. https:// doi.org/10.1097/MOL.0000000000000392
19. Bundesministerium für Gesundheit (2008) Bekanntmachung eines Beschlusses des Gemeinsamen Bundesausschusses über eine Änderung der Richtlinie Methoden vertragsärztliche Versorgung: Apherese bei isolierter Lp(a)-Erhöhung. BAnz.138:3321

20. Julius U, Tselmin S, Schatz U, Fischer S, Bornstein SR (2019) Lipoprotein(a) and proprotein convertase subtilisin/kexin type 9 (PCSK9) inhibitors. Clin Res Cardiol Suppl. https://doi.org/10. 1007/s11789-019-00099-z

21. Jaeger BR, Richter Y, Nagel D, Heigl F, Vogt A, Roeseler E et al (2009) Longitudinal cohort study on the effectiveness of lipid apheresis treatment to reduce high lipoprotein(a) levels and prevent major adverse coronary events. Nat Clin Pract Cardiovasc Med 6(3):229-239

22. Leebmann J, Roeseler E, Julius U, Heigl F, Spitthoever R, Heutling D et al (2013) Lipoprotein apheresis in patients with maximally tolerated lipid-lowering therapy, lipoprotein(a)-hyperlipoproteinemia, and progressive cardiovascular disease: prospective observational multicenter study. Circulation 128(24):2567-2576

23. Roeseler E, Julius U, Heigl F, Spitthoever R, Heutling D, Breitenberger P et al (2016) Lipoprotein apheresis for lipoprotein(a)associated cardiovascular disease: prospective 5 years of followup and apo(a) characterization. Arterioscler Thromb Vasc Biol 26:2019-2027. https://doi.org/10.1161/ATVBAHA.116.307983

24. von Dryander M, Fischer S, Passauer J, Muller G, Bornstein SR, Julius U (2013) Differences in the atherogenic risk of patients treated by lipoprotein apheresis according to their lipid pattern. Atheroscler Suppl 14(1):39-44. https://doi.org/10.1016/j. atherosclerosissup.2012.10.005

25. Emmrich U, Hohenstein B, Julius U (2015) Actual situation of lipoprotein apheresis in Saxony in 2013. Atheroscler Suppl 18:215-225. https://doi.org/10.1016/j.atherosclerosissup.2015.02. 034

26. Schatz U, Tselmin S, Muller G, Julius U, Hohenstein B, Fischer S et al (2017) Most significant reduction of cardiovascular events in patients undergoing lipoproteinapheresis due to raised Lp(a) levels-A multicenter observational study. Atheroscler Suppl 30:246-252. https://doi.org/10.1016/j.atherosclerosissup.2017.05. 047

27. Julius U (2018) Current role of lipoprotein apheresis in the treatment of high-risk patients. J Cardiovasc Dev Dis. https://doi.org/ 10.3390/jcdd5020027

28. Tsimikas S, Viney NJ, Hughes SG, Singleton W, Graham MJ, Baker BF et al (2015) Antisense therapy targeting apolipoprotein(a): a randomised, double-blind, placebo-controlled phase 1 study. Lancet 386(10002):1472-1483. https://doi.org/10.1016/ S0140-6736(15)61252-1

29. Viney NJ, van Capelleveen JC, Geary RS, Xia S, Tami JA, Yu RZ et al (2016) Antisense oligonucleotides targeting apolipoprotein(a) in people with raised lipoprotein(a): two randomised, doubleblind, placebo-controlled, dose-ranging trials. Lancet 388(10057): 2239-2253. https://doi.org/10.1016/S0140-6736(16)31009-1

30. Marcovina SM, Viney NJ, Hughes SG, Xia S, Witztum JL, Tsimikas S (2018) Temporal variability in lipoprotein(a) levels in patients enrolled in the placebo arms of IONIS-APO(a)Rx and IONIS-APO(a)-LRx antisense oligonucleotide clinical trials. J Clin Lipidol 12(1):122-129.e2. https://doi.org/10.1016/j.jacl.2017.10. 024

31. Mazhar Z, Hughes A, Garelnabi M (2017) Targeting the role of lipoprotein (a) in stroke. Cardiovasc Hematol Disord Drug Targets 17(1):64-72. https://doi.org/10.2174/1871529X176661704211 50028

32. Sultan SM, Schupf N, Dowling MM, Deveber GA, Kirton A, Elkind MS (2014) Review of lipid and lipoprotein(a) abnormalities in childhood arterial ischemic stroke. Int J Stroke 9(1):79-87. https://doi.org/10.1111/ijs.12136 
33. Fanshawe AE, Ibrahim M (2013) The current status of lipoprotein (a) in pregnancy: a literature review. J Cardiol 61(2):99-106. https://doi.org/10.1016/j.jjcc.2012.09.009

34. Parvin S, Samsuddin L, Ali A, Chowdhury SA, Siddique I (2010) Lipoprotein (a) level in pre-eclampsia patients. Bangladesh Med Res Counc Bull 36(3):97-99

35. Schettler VJ, Schulz EG, Hagenah GC, Neumann CL (2014) Successful completion of pregnancy using apheresis and a balanced dose of coagulation factors in the presence of high thrombophilia and $\mathrm{Lp}$ (a) levels in a woman with two previous abortions. Clin Kidney J 7(5):497-498. https://doi.org/10.1093/ckj/sfu083

36. Romagnuolo I, Sticchi E, Attanasio M, Grifoni E, Cioni G, Cellai AP et al (2016) Searching for a common mechanism for placentamediated pregnancy complications and cardiovascular disease: role of lipoprotein(a). Fertil Steril 105(5):1287-1293.e3. https://doi.org/ 10.1016/j.fertnstert.2016.01.014
37. Julius U, Fritsch H, Fritsch W, Rehak E, Fucker K, Leonhardt $\mathrm{W}$ et al (1994) Impact of hormone replacement therapy on postprandial lipoproteins and lipoprotein(a) in normolipidemic postmenopausal women. Clin Investig 72(7):502-507

38. Ellis KL, Pang J, Chieng D, Bell DA, Burnett JR, Schultz CJ et al (2018) Elevated lipoprotein(a) and familial hypercholesterolemia in the coronary care unit: Between Scylla and Charybdis. Clin Cardiol 41(3):378-384. https://doi.org/10.1002/clc.22880

39. Heigl F, Pflederer T, Schettler V, Grutzmacher P, Julius U, Ringel $\mathrm{J}$ et al (2017) Lipidological competence centres and networks: Future perspectives to improve healthcare of patients with disorders of lipid metabolism. Atheroscler Suppl 30:63-71. https://doi.org/ 10.1016/j.atherosclerosissup.2017.05.014 